OPEN ACCESS

Edited by:

Deepak Kaushal,

Southwest National Primate Research Center (SNPRC), United States

Reviewed by:

LiYe,

Guangxi Medical University, China Nelita Du Plessis,

Stellenbosch University, South Africa

${ }^{*}$ Correspondence: Ankita Garg agarg@uga.edu

${ }^{\dagger}$ Present address: Brandi Sparling,

College of Veterinary Medicine, Western University of Health Sciences,

Pomona, CA, United States

Specialty section:

This article was submitted to Microbial Immunology, a section of the journal

Frontiers in Immunology

Received: 28 December 2020 Accepted: 06 April 2021 Published: 28 April 2021

Citation:

Namdev $P$, Patel S, Sparling B and Garg A (2021) Monocytic-Myeloid Derived Suppressor Cells of HIV-Infected Individuals

With Viral Suppression Exhibit Suppressed Innate Immunity to Mycobacterium tuberculosis.

Front. Immunol. 12:647019. doi: 10.3389/fimmu.2021.647019

\section{Monocytic-Myeloid Derived Suppressor Cells of HIV-Infected Individuals With Viral Suppression Exhibit Suppressed Innate Immunity to Mycobacterium tuberculosis}

\author{
Priyanka Namdev ${ }^{1}$, Shiv Patel ${ }^{2}$, Brandi Sparling ${ }^{1 \dagger}$ and Ankita Garg ${ }^{1 *}$ \\ 1 Department of Infectious Diseases, College of Veterinary Medicine, University of Georgia, Athens, GA, United States, \\ 2 Franklin College of Arts and Sciences, University of Georgia, Athens, GA, United States
}

Tuberculosis can occur during any stage of Human Immunodeficiency virus 1 (HIV) -infection including times when $\mathrm{CD}^{+}{ }^{+} \mathrm{T}$ cell numbers have reconstituted and viral replication suppressed. We have previously shown that $C D 11 b^{+} C D 33^{+} C D 14^{+} H L A-D R^{-/ 10}$ monocytic myeloid-derived suppressor cells (MDSC) persist in HIV-infected individuals on combined anti-retroviral therapy (cART) and with virologic suppression. The response of MDSC to Mycobacterium tuberculosis (Mtb) is not known. In this study, we compared the anti-mycobacterial activity of MDSC isolated from HIV -infected individuals on cART with virologic suppression (HIV MDSC) and HIV-uninfected healthy controls (HIV (-) MDSC). Compared to HIV (-) MDSC, HIV MDSC produced significantly less quantities of antimycobacterial cytokines IL-12p70 and TNF $\alpha$, and reactive oxygen species when cultured with infectious Mtb or Mtb antigens. Furthermore, HIV MDSC showed changes in the Tolllike receptor and IL-27 signaling, including reduced expression of MyD88 and higher levels of IL-27. Neutralizing IL-27 and overexpression of MyD88 synergistically controlled intracellular replication of Mtb in HIV MDSC. These results demonstrate that MDSC in fully suppressed HIV-infected individuals are permissive to Mtb and exhibit downregulated anti-mycobacterial innate immune activity through mechanisms involving IL-27 and TLR signaling. Our findings suggest MDSC as novel mediators of tuberculosis in HIV-Mtb coinfected individuals with virologic suppression.

Keywords: HIV-1, myeloid derived suppressor cell, IL-27, M tuberculosis, people living with HIV (PLWH), innate immunity

\section{INTRODUCTION}

Infection with Mycobacterium tuberculosis and human immunodeficiency virus-1 (HIV) constitute major burdens of infectious disease in resource-limited countries $(1,2)$. Co-infection with HIV increases the risk of developing tuberculosis (TB) between 16-27 times $(1,3)$. It is intriguing that TB can occur in the settings of HIV at any disease state and irrespective of $\mathrm{CD} 4^{+} \mathrm{T}$-cell numbers (4-8). 
The profound immune suppression during HIV-infection is considered critical for increased risk of developing TB. Paradoxically, exaggerated proinflammatory responses to $M$ tuberculosis in HIV-infection remain inefficient to control TB (911). The loss of $M$ tuberculosis specific $\mathrm{CD} 4^{+} \mathrm{T}$-cells and inability of producing perforin by $\mathrm{CD} 8^{+} \mathrm{T}$-cells during acute $\mathrm{HIV}$ infection (12-14), and impaired phagolysosomal fusion, autophagy mediated inhibition of $M$ tuberculosis and impaired generation of antimicrobial peptide and mycobactericidal reactive radicals in HIV- $M$ tuberculosis co-infected macrophages are considered to increase the risk of TB (15-20). However, explanation for the impaired immunity to $M$ tuberculosis in clinically recovered HIV patients remains unresolved.

Increasing evidence establish accumulation of

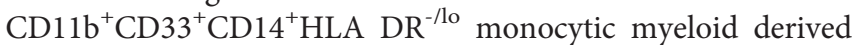
suppressor cells (MDSC) in inflammatory clinical conditions (2124). Besides suppressing T-cell functions, MDSC down regulate antigen presentation, IL-12 production, and augment IL-10 production from macrophages (25-28). Previously we showed that MDSC expand in HIV-infected individuals with replicating virus in an IL-6 dependent manner (29), and continue to remain elevated in HIV (+) individuals on combined antiretroviral therapy (cART), with suppressed viral replication and reconstituted $\mathrm{CD} 4^{+}$ $\mathrm{T}$-cell numbers $(30,31)$. Immune activation and hyperinflammation characterized by elevated levels of soluble tumor necrosis factor receptor II (TNF-RII), neopterin, soluble IL-2R, sCD163, sCD14, IL-6, IP-10 predict disease progression in untreated HIV infection and mediate expansion of MDSC. Of note, IL-6 levels remain elevated in HIV-infected individuals despite successful cART and is responsible for sustained increase in MDSC number as compared to healthy controls. Recent animal and human studies establish peripheral and tissue accumulation of MDSC during infection with Mtb $(25,32,33)$. These MDSC are permissive to Mycobacterium and suppress T cell responses to Mtb antigens, thus contributing to TB disease progression. The anti-Mtb innate immunological response of MDSC in HIV-infected persons with virological suppression remains unknown.

In the present study, we compared the anti- $M$ tuberculosis activity of MDSC isolated from HIV uninfected (HIV -) and $\mathrm{HIV}$-infected $(\mathrm{HIV}+)$ individuals on cART with undetectable HIV RNA copies and recovered $\mathrm{CD}^{+} \mathrm{T}$-cells. We found that compared to MDSC isolated from HIV (-) individuals (HIV (-) MDSC), MDSC isolated from HIV(+) (HIV MDSC) are defective in innate immune mediated control of Mtb. We further show that HIV MDSC have a higher expression of IL-27 receptor (IL-27R); thus IL-27-IL27R axis increase the risk of mycobacterial disease in $\mathrm{HIV}$-infected individuals.

\section{MATERIALS AND METHODS}

\section{Patient Groups}

Blood was obtained after written informed consent from Quantiferon ${ }^{\circledR}$-TB negative HIV-uninfected (HIV-) and HIVinfected $(\mathrm{HIV}+)$ persons on cART with virologic suppression and $\mathrm{CD}^{+}$. All studies were conducted in accordance with the
Declaration of Helsinki guidelines and approved by Institutional Review Board of the University of California San Diego and Institutional Review Board of the University of Georgia Athens.

\section{Antibodies and Other Reagents}

For flow cytometry, Alexa Fluor 488/anti-CD11b, APC or Alexa Fluor 700/anti-CD33, BV605/anti-CD3, BV510/anti-CD19, PerCPCy5.5/anti-CD66b, PE/Cy7/anti-CD14, PE/Dazzle594/ anti-HLA DR (all from Biolegend); APC-eFluor 780/antiCD11b, PE/anti-TLR2, Alexa Fluor 488/anti-TLR4 (all from Thermo Fisher Scientific) and APC/anti-IL27R from R\&D systems were used. For live/dead staining we used LIVE/ DEAD $^{\mathrm{TM}}$ Fixable Aqua Dead cell stain, and for reactive oxygen species CellROX ${ }^{\mathrm{TM}}$ Deep Red Reagent, both from Thermo Fisher Scientific. For immunoblotting, anti- IL-27A (Abcam), phosphorylated (p) NF- $\kappa$ B, NF- $\kappa$ B, STAT1 and pSTAT1 (all from R\&D Systems), STAT3 (Novus) pSTAT3 and GAPDH (Cell Signaling Technology) were used.

\section{Isolation and Culture of $\mathrm{CD}^{11 b^{+} \mathrm{CD}^{+} 3^{+} \mathrm{CD} 14^{+} \mathrm{HLA}-\mathrm{DR}}{ }^{-/ 10}$ (MDSC) and $\mathrm{CD} 11 \mathrm{~b}^{+} \mathrm{CD}^{3} 3^{+} \mathrm{CD} 14^{+} \mathrm{HLA}-\mathrm{DR}{ }^{+/ h i}$ (Monocytes)}

Peripheral blood mononuclear cells were stained for CD11b, CD33, CD14, HLA-DR; CD $11 b^{+} \mathrm{CD} 33^{+} \mathrm{CD} 14^{+} \mathrm{HLA} \mathrm{DR} \mathrm{DR}^{-/ \mathrm{lo}}$

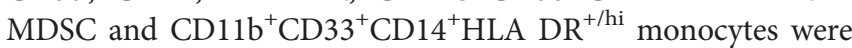
isolated using Beckman Coulter MoFlo flow cytometer; sorted cells were $>90 \%$ positive (Supplemental Figure 1). Isolated cells (50, $000-80,000)$ were cultured in RPMI 1640 (Gibco) and 10\% human serum (MP Biomedicals) at $37^{\circ} \mathrm{C}$ and $5 \% \mathrm{CO}_{2}$ in the presence or absence of, $M$ tuberculosis Erdman (Erdman) or $M$ tuberculosis $\mathrm{H} 37 \mathrm{Rv}$ whole cellular lysate (WCL) $(10 \mu \mathrm{g} / \mathrm{ml})(\mathrm{BEI}$ resources) for $24 \mathrm{hrs}$. Supernatants and cells in Trizol were stored at $-80^{\circ} \mathrm{C}$ for cytokine measurement and RNA purification, respectively. For some experiments, cells were cultured in the absence or presence of recombinant IL-27 (rIL-27) $(10 \mathrm{ng} / \mathrm{ml}$; R\&D Systems).

\section{Infection of Cells and Measurement of Intracellular Mycobacterial Growth}

MDSC $\left(0.1 \times 10^{5} /\right.$ well $)$ were plated in 48 -well plates in antibiotic free RPMI 1640 medium and 10\% human serum. Cells were infected with Erdman at a multiplicity of infection (MOI) of 1:5 for $3 \mathrm{hrs}$; subsequently, cells were washed and treated with Gentamycin Sulfate $(30 \mu \mathrm{g} / \mathrm{ml}$; VWR Life Sciences) for additional 2-hours to kill extracellular bacteria, and cultured in RPMI 1640 with $10 \%$ human serum. Cells were lysed with $0.1 \%$ SDS at day-0 and day -3 or day -5 post-infection, and cellular lysates were serially diluted and plated in triplicate on Middlebrook $7 \mathrm{H} 10$ agar supplemented with OADC enrichment. The number of colonies were counted after 3 weeks and colony forming units (CFU)/ml determined.

\section{Overexpression of MyD88}

MyD88 was overexpressed in MDSC by transfecting pUNO1hMYD88 (InvivoGen) expression plasmid using Lipofectamine 
3000 (from Thermo Fisher Scientific). Briefly, 1 $\mu$ g MyD88 or empty vector plasmid DNA was diluted in $\mathrm{P} 3000^{\mathrm{TM}}$ reagent and Lipofectamine 3000 in Opti-MEM medium. Diluted plasmid and Lipofectamine were mixed in 1:1 ratio, and incubated for $15 \mathrm{~min}$ at room temperature. The plasmid-lipid complex was added to cells and incubated at $37^{\circ} \mathrm{C}$ and $5 \% \mathrm{CO}_{2}$.

\section{Immunolabelling, Flow Cytometry and ROS}

Cells were surface stained for CD11b, CD33, CD14, HLA-DR, using cell staining buffer and respective antibodies. Controls for each experiment included unstained cells and fluorescence minus one (FMO) (29).

For ROS, sorted MDSC were infected with Green Fluorescence Protein expressing Mtb Erdman (GFP-Mtb) at MOI of 1:5 for 2-hrs. During the last 30-min of infection, cells were incubated with $1 \mu \mathrm{M}$ of CellROX ${ }^{\mathrm{TM}}$ Deep Red reagent at $37^{\circ} \mathrm{C} / 5 \% \mathrm{CO}_{2}$ and subsequently stained with aqua fluorescent LIVE/DEAD fixable dye. All the procedures were performed in Biosafety Level-3 and samples were analyzed on flow cytometer following the institutional biosafety guidelines. Dead cells were excluded and expression of CellROX was analyzed in $\mathrm{GFP}^{+} \mathrm{Mtb}$ cell gate; Net ROS expression $=$ [Mean fluorescence intensity of ROS by $\mathrm{GFP}^{+}$Mtb MDSC - Mean fluorescence intensity of ROS by uninfected MDSC] (34).

\section{Immunoblotting}

Immunoblotting of cell lysates was performed as previously described (30). Relative densities for target protein bands IL27A (molecular weight $27 \mathrm{kDa}$ ), NF- $\mathrm{BB}$ p65/phosphorylated $\left(\mathrm{p}^{\mathrm{S} 536}\right.$ ) NF- $\mathrm{kB}$ p65 (molecular weight $65 \mathrm{kDa}$ ), STAT1/ $\mathrm{p}^{\mathrm{Y} 701}$ STAT1 (molecular weight $90 \mathrm{kDa}$ ) or STAT3/p ${ }^{\text {Y705 STAT3 }}$ (molecular weight $95 \mathrm{kDa}$ ) to housekeeping GAPDH (molecular weight $37 \mathrm{kDa}$ ) bands were compared using ImageJ (NIH). Fold change was determined as: normalized density in unstimulated cells/normalized density in WCL or rIL-27 stimulated cells.

\section{Quantification of Cytokines}

IL-12p70, TNF $\alpha$, IL-6, IL-23 and IL-1 $\beta$ was determined in the culture supernatants at 24 hrs-post infection using LUMINEX multiplex system (R\&D Systems) and custom designed kit. The fold change in cytokine was determined in $M$ tuberculosis treated cells as: cytokine by Erdman infected or WCL treated cells/ cytokine by uninfected or unstimulated controls. The quantity of IL-27 in the plasma was measured using Duoset ELISA kit (R\&D Systems catalog DY2526).

\section{Quantitative Real Time PCR (qRT PCR)}

Total RNA was isolated from MDSC using TRIzol ${ }^{\mathrm{TM}}$ reagent (Thermo Fisher Scientific) according to manufacturer's protocol; 100-250 ng RNA was used in $20 \mu \mathrm{l}$ of reverse transcription reaction using SuperScript ${ }^{\mathrm{TM}}$ IV VILO ${ }^{\mathrm{TM}}$ with ezDNAse Reverse Transcription kit (Thermo Fisher Scientific). TaqMan Gene expression Assay (Thermo Fisher Scientific) were used for qPCR analysis (Table 1). The changes in the threshold cycle $\left(\mathrm{C}_{\mathrm{T}}\right)$ were calculated by the equation $\Delta \mathrm{C}_{\mathrm{T}}=\mathrm{C}_{\mathrm{T} \text {,target }}{ }^{-} \mathrm{C}_{\mathrm{T} 18 \mathrm{~S}}$ for control and WCL stimulated cells, $\Delta \Delta \mathrm{C}_{\mathrm{T}}=\Delta \mathrm{C}_{\mathrm{T}, \mathrm{WCL}}-\Delta \mathrm{C}_{\mathrm{T}}$, control. The fold change was calculated as $2^{-\left(\Delta \triangle C_{T}\right)}$.
TABLE 1 | TaqMan Gene Expression Assays (Life Technologies) used for RT PCR.
Gene

18S RNA

MyD88

NFKB1A
TaqMan Assay

Hs99999901_s1 Hs01573837_g1 Hs00355671_g1

\section{Statistical Analysis}

Data are expressed as mean values \pm standard error mean (SEM). Paired Student's t-tests were used to determine the statistical significance for in vitro experiments. Comparisons between HIV (-) and HIV (+) using Mann-Whitney $U$ test. Statistical analysis was performed using Graphpad Prism 8 (La Jolla, CA). P-values of $<0.05$ were considered statistically significant.

\section{RESULTS}

\section{Innate Immune Activity of MDSC in Response to $M$ tuberculosis}

We have previously established that HIV-infected person with virologic suppression as a result of successful cART exhibit increased circulating numbers of MDSC which regulate immune response to HIV-associated opportunistic pathogen (30). Herein we sought to investigate and compare the response of HIV (-) MDSC and HIV MDSC to $M$ tuberculosis. For this, in the initial set of experiments we isolated HIV (-) and HIV MDSC, in vitro infected them with $M$ tuberculosis or stimulated with $M$ tuberculosis whole cell lysate antigen (WCL) and measured cytokines in the culture supernatants; the fold change in response to $M$ tuberculosis or WCL was determined. The sorted MDSC were $>95 \%$ pure (Supplemental Figure 1). Similar to a previous report, we found HIV MDSC produced inflammatory cytokines in response to $M$ tuberculosis; however, compared to HIV (-) MDSC, fold increase in IL-12p70 and TNF $\alpha$ quantities produced by HIV MDSC infected with live $M$ tuberculosis was less $(1.2 \pm 0.1$ vs $2.2 \pm 0.4 ; \mathrm{p}=0.001$ for IL-12p70, and $248.5 \pm 166$ vs $556.4 \pm 265.4$; $\mathrm{p}=0.04$ for TNF $\alpha$ ). However, the fold increase in IL- $1 \beta$ produced by HIV MDSC as compared to HIV (-) MDSC was more (61.7 \pm 32 vs $29.4 \pm 6.5$; $\mathrm{p}=0.02)$. IL-6 produced by HIV MDSC was also higher than HIV (-) MDSC, but was not significant ( $15.3 \pm 9.6$ vs $7.4 \pm 4$; $\mathrm{p}=0.6)$ (Figure 1A). Importantly, similar pattern was observed when these cells were cultured with WCL (Figure 1B) which further suggests that HIV MDSC are responsive to $M$ tuberculosis antigens and do not require active mycobacterial replication for downregulated cytokine production. Of note, quantities of anti-mycobacterial cytokines TNF $\alpha$ and IL-12p70 produced by HIV MDSC was significantly less than that produced by HLA DR ${ }^{\text {hi }}$ monocytes (Supplemental Figures 2A, B). Collectively, these findings suggest that despite preservation of $\mathrm{CD}^{+} \mathrm{T}$ cells and virologic suppression, HIV MDSC exhibit dysregulated anti$M$ tuberculosis cytokine response.

Reactive oxygen species (ROS) is critical for the control of $M$ tuberculosis early in infectious process, and ROS production by 
A

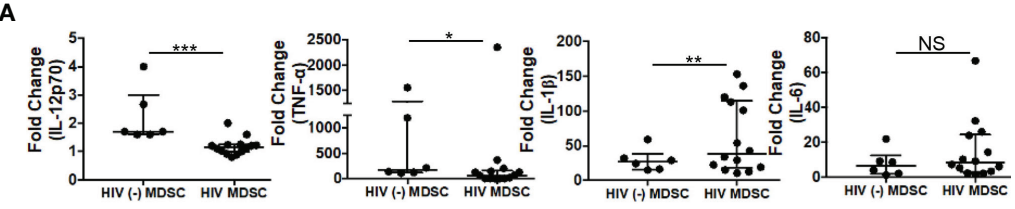

B

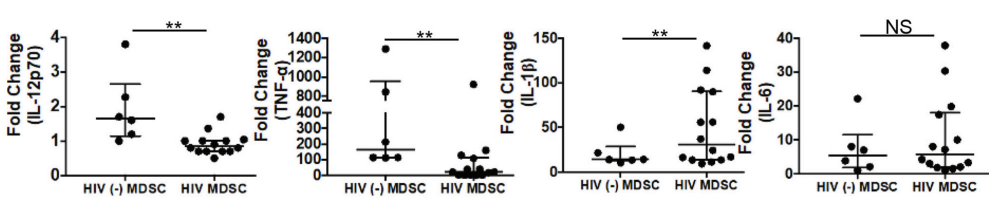

C

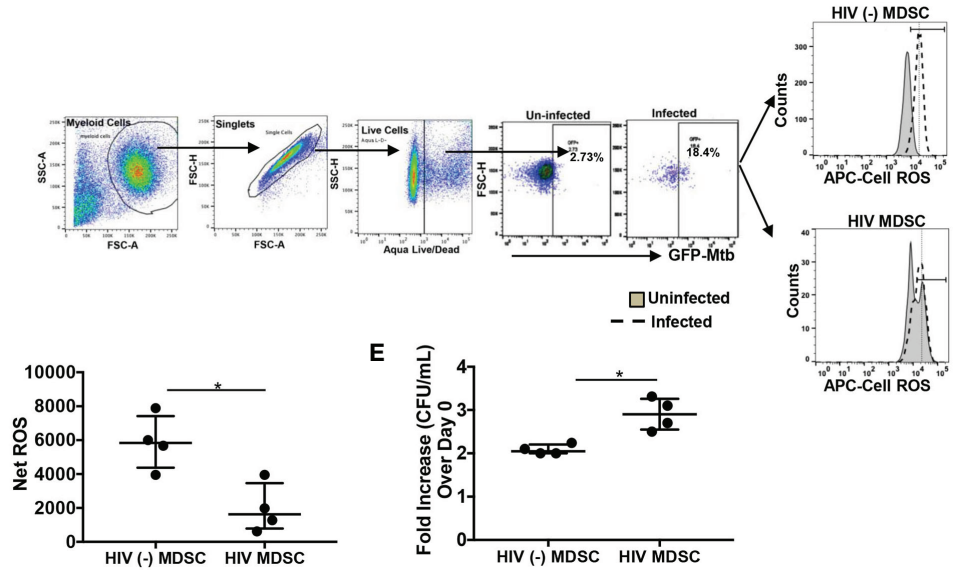

FIGURE 1 | Suppressed innate immunity of HIV MDSC in response to $M$ tuberculosis. PBMC from HIV (-) and HIV (+) donors on cART and with virologic suppression was surface stained with anti-CD -11b, $-33,-14$ and HLA DR antibodies. CD11 $\mathrm{b}^{+} \mathrm{CD} 33^{+} \mathrm{CD} 14^{+} \mathrm{HLA} \mathrm{DR}^{-1 / 0} \mathrm{MDSC}$ were isolated by flow cytometry and named as HIV (-) MDSC and HIV MDSC, respectively. (A, B) Cells were either infected with M tuberculosis (A) or cultured with M tuberculosis whole cell lysate (B). The amount of cytokines were measured in the culture supernatants and fold change was calculated as Quantity in presence of $M$ tuberculosis/Quantity in absence of M tuberculosis. (C, D) MDSC were infected with GFP expressing M tuberculosis (Mtb-GFP) at multiplicity of infection (MOI) 1:5 for 2-hrs. During last 30-mins of infection $1 \mu \mathrm{M}$ of CellROX deep read reagents was added and subsequently stained with aqua fluorescent LIVE/DEAD stain. Expression of ROS (CellROS) in Mtb-GFP+ Live cells was determined by flow cytometry (MFI, Mean Fluorescence Intensity). Net ROS expression was calculated as in Materials and Methods. Representative flow cytometry plot of one HIV (-) MDSC and HIV MDSC donor is shown; vertical line is median. (E) MDSC cells were infected with M tuberculosis at $\mathrm{MOI}$ of 1:5 for 3-hrs, washed with PBS to remove extracellular bacteria, $M$ tuberculosis growth (colony forming units (CFU)/ml) was determined in the cellular lysates at day-0 and day-5 post-infection. The fold increase in intracellular bacterial replication was measured as CFU/ml at Day-0/CFU/ml at Day-5. For (A, B, D, E), each dot representing an individual donor include observations from $25^{\text {th }}$ to $75^{\text {th }}$ percentile; the horizontal line represents the median value. ${ }^{*} p<0.05,{ }^{* *} p<0.005$, ${ }^{\star \star \star} \mathrm{p}<0.0005$. NS, Non Significant.

myeloid cells is regulated by cytokines in TLR-dependent manner (35-39). Therefore, we next compared intracellular ROS produced by $M$ tuberculosis infected HIV (-) MDSC and HIV MDSC. For these studies we used GFP-Mtb and measured cellular ROS by flow cytometry. Similar to our previous findings (29), HIV MDSC as compared to HIV (-) MDSC produced more ROS (Supplemental Figure 2C). However, the expression of ROS in GFP-Mtb ${ }^{+}$HIV MDSC was less when compared to HIV (-) MDSC (1957.3 \pm 721 vs $5880 \pm 807$; $\mathrm{p}=0.04$ ) (Figures 1C, D). All together, these findings establish that HIV MDSC exhibit downregulated innate immune response to $M$ tuberculosis.

\section{Increased Intracellular Replication of $M$ tuberculosis in MDSC}

Our studies demonstrate MDSC isolated from HIV-infected individuals exhibit downregulated anti-mycobacterial innate immune response. Therefore, in the next set of experiments we determined and compared the intracellular growth of $M$ tuberculosis in HIV (-) MDSC and HIV MDSC. As compared to day-0, a 3- fold higher CFU of $M$ tuberculosis was found in the cellular lysates of HIV MDSC and 2- fold in HIV (-) MDSC at day -5 post-infection (p.i.) $(3.0 \pm 0.2$ vs $2.0 \pm 0.06$; $\mathrm{p}=0.02$ ) (Figure 1E). These findings suggest that despite virologic suppression, HIV MDSC are inefficient to control $M$ tuberculosis replication.

\section{MDSC Exhibit Truncated TLR Signaling}

To determine if the reduced anti-mycobactericidal activity and cytokine response of HIV MDSC observed in Figures 1A-E is due to the defect in TLR signaling (40-42), we evaluated the surface expression of TLR-2 and -4 on HIV MDSC and compared their expression on HIV (-) MDSC, by flow 
cytometry. The expression of TLR-2 on HIV MDSC was higher as compared to its expression on HIV (-) MDSC (MFI $1887.3 \pm 311.3$ vs $525 \pm 177.7$; $=0.004$ ) (Figures 2A, B). However, the expression of TLR-4 on HIV MDSC and HIV (-) MDSC (MFI $374.7 \pm 75.4$ vs $266 \pm 77$; $\mathrm{p}=0.24$ ) (Figures 2C, D) was comparable. Unlike TNF $\alpha$ and IL-12p70 cytokine quantities, the expression of TLR-2 and -4 was comparable on HIV MDSC and HIV HLA DR ${ }^{\text {hi }}$ monocytes (Supplemental Figures 3A, B)

Despite a higher expression of TLR-2, HIV MDSC produced less anti- $M$ tuberculosis cytokines, we questioned if the differences occur in the expression of cytoplasmic adapter protein MyD88 (42, 43). Since our cytokine studies (Figures 1A, B) demonstrate similar anti-mycobacterial activity in response to infectious or non-infectious $M$ tuberculosis. Therefore, for gene expression assays, we cultured these cell types with WCL for 24-hrs and quantified messenger RNA (mRNA) for MyD88 by qRT PCR. HIV (-) MDSC cultured with WCL exhibited a 3.3-fold increased expression of MyD88 as compared to unstimulated controls; the expression of MyD88 in HIV MDSC cultured with WCL was less than HIV (-) MDSC $(1.22 \pm 0.5$ vs $3.3 \pm 1.5 ; \mathrm{p}=0.04)$ (Figure $2 \mathrm{E}$ ) and HIV HLA DR ${ }^{\text {hi }}$ monocytes (Supplemental Figure 3C). Downstream of TLRsignaling and pivotal for the synthesis of proinflammatory cytokines and ROS, is the activation and nuclear transport of the transcription factor NF- $\mathrm{KB}$, which is regulated by the degradation of

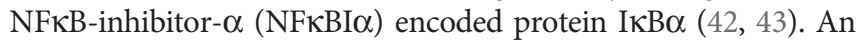
increase in NFKBI $\alpha$ expression inhibits the degradation of $I \kappa B \alpha$ thus sequestering NF- $\kappa \mathrm{B}$ in the cytoplasm and inhibition in proinflammatory cytokine production (37-39). In order to establish that reduced quantities of cytokine produced by HIV MDSC is due to insufficient NF- $\kappa B$ activation, we quantified mRNA for NFKBI $\alpha$ in response to WCL by RT PCR in HIV MDSC and HIV (-) MDSC. HIV MDSC compared to HIV HLA DR ${ }^{\text {hi }}$ monocytes (Supplemental Figure 3D), and HIV (-) MDSC exhibited a 5-fold increased expression of NFKBI $\alpha$ in response WCL $(4.8 \pm 0.8$ vs $2.1 \pm 0.7 ; \mathrm{p}=0.05$ ) (Figure $2 \mathbf{F}$ ). This was accompanied by less phosphorylation of NF- $\kappa \mathrm{B}$ p65 in HIV MDSC cultured with WCL (Figures 2G, $\mathbf{H}$ ).

Next, we overexpressed MyD88 by transfecting expression plasmid containing open reading frame of human MyD88 in HIV MDSC and measured the intracellular replication of $M$ tuberculosis at 72-hrs post-infection. Compared to MDSC transfected with control plasmid, MyD88 transfection decreased the intracellular replication of $M$ tuberculosis, but this was not significant $\left(50 \times 10^{4} \pm\right.$ $17 \times 10^{3}$ vs $28 \times 10^{4} \pm 14 \times 10^{3} \mathrm{CFU} / \mathrm{ml}, \mathrm{p}=0.06$ ) (Figure 2I). Collectively, these studies establish that the impaired antimycobacterial innate immune response of HIV MDSC is due to the reduced expression of MyD88, and reconstituting it partially restores the anti-mycobacterial function of HIV MDSC.

\section{IL-27 and MDSC}

IL-27 is an immune regulatory cytokine that inhibits phagosomal activity of macrophages in response to bacterial infection including Mycobacterium (44, 45). In HIV-infection, we previously showed that the plasma IL-27 level correlates positively with $\mathrm{CD}^{+}$T-cell count and negatively with HIV- viral load (30). We sought to determine if IL-27 inhibits antimycobacterial activity of HIV MDSC. To this end, initially we quantified the amount of IL-27 in the plasma of HIV-infected individuals and in healthy controls. Compared to healthy controls, the quantity of IL-27 in the plasma of HIV-infected individuals was high $(4.6 \pm 1.7$ vs $17.7 \pm 7 \mathrm{ng} / \mathrm{ml} ; \mathrm{p}=0.03)$ (Figure 3A). Next, we measured IL-27 in the culture supernatants of HIV MDSC and HIV (-) MDSC infected with $M$ tuberculosis or stimulated with WCL as in Figures 1A, B; IL27 in these culture supernatants was undetectable. However, we observed increased expression of IL-27 in the cellular lysates of HIV MDSC in vitro stimulated with WCL (Figures 3B, C).

Additionally, we measured the surface expression of IL-27R on HIV MDSC and HIV (-) MDSC isolated from HIV-infected and HIV-uninfected individuals, respectively, by flow cytometry. The expression of IL-27R on HIV MDSC was high (MFI $938.5 \pm 130 \mathrm{vs}$ $481 \pm 73 ; \mathrm{p}=0.03$ ) (Figures 3D, E) as compared to HIV (-) MDSC, and HIV HLA DR ${ }^{\text {hi }}$ monocytes (Supplemental Figure 3E). IL-27R is indispensable for IL-27 signaling, which induces phosphorylation of STAT1 and STAT3 in myeloid cells $(46,47)$. In order to establish the functional significance of increased expression of IL27R on HIV MDSC, we stimulated HIV (-) MDSC and HIV MDSC with rIL-27 for 30 mins and assessed pSTAT1 and pSTAT3 in cellular lysates. Compared to unstimulated and rIL-27 stimulated HIV (-) MDSC, HIV MDSC exhibited increased pSTAT1 and pSTAT3 (Figures 3F-I) expression. Collectively, these findings suggest that IL-27 may modulate the anti-mycobacterial activity of MDSC in clinically recovered HIV-infected individuals.

\section{IL-27 Inhibits Anti-Mycobacterial Activity of MDSC}

Our initial findings established reduced proinflammatory cytokines, ROS and increased IL-27 by HIV MDSC in response to $M$ tuberculosis; we argued if IL-27 suppresses ROS activity. To evaluate this, we infected HIV (-) MDSC and HIV MDSC with GFP-Mtb in the presence or absence of neutralizing IL-27 or isotype matched control antibody and measured intracellular ROS by flow cytometry as in Figure 1D. Consistent with our findings of Figure 1D, GFP-Mtb+ HIV (-) MDSC compared to HIV MDSC express more ROS (MFI $5209.7 \pm 647.4$ vs $2407 \pm 217 ; \mathrm{p}=0.05$ ). The expression of ROS increased in both HIV (-) MDSC and HIV MDSC upon neutralization of IL-27 (MFI $5209.7 \pm 647.4$ vs $8147.7 \pm 1138.6 ; \mathrm{p}=0.02$ and $2407 \pm 217$ vs $4030.7 \pm 320$; $\mathrm{p}=0.03$, respectively) (Figure 4A). Of note, IL-27 neutralization increased the ROS expression of HIV MDSC in response to $M$ tuberculosis but its level remained lower than HIV (-) MDSC (MFI $4030.7 \pm 320$ vs $5209.7 \pm 647.4 ; \mathrm{p}=0.05$ ).

Since overexpression of MyD88 in HIV MDSC partially inhibited intracellular replication of $M$ tuberculosis (Figure 2F), we further investigated if IL-27 plays a role in anti-mycobacterial activity of MDSC. For this, MDSC isolated from HIV-infected individuals were infected with $M$ tuberculosis and treated with neutralizing IL-27 or isotype matched control antibody; intracellular $M$ tuberculosis replication was determined at day-3 post-infection. Compared to isotype matched control, lower $\mathrm{CFU} / \mathrm{ml}$ were found in the cellular lysates of MDSC infected 


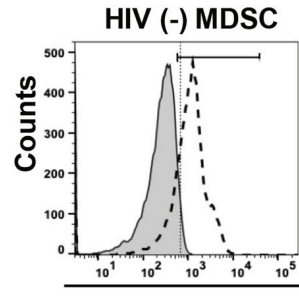

C

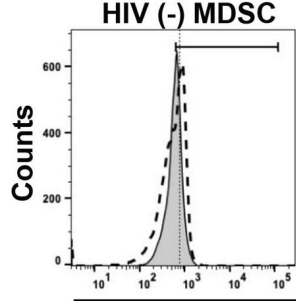

E

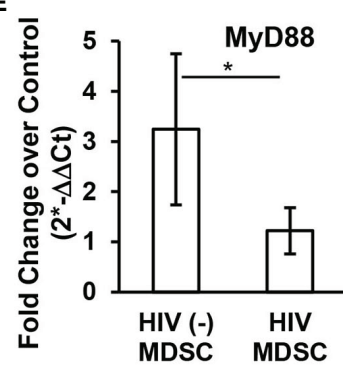

HIV MDSC

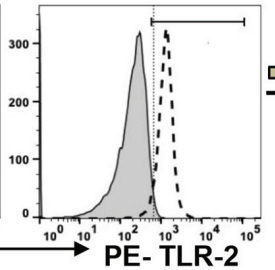

HIV MDSC

- $-\underset{\text { TLR }}{\mathrm{TLO}}$

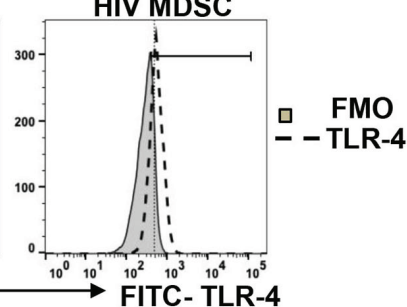

F

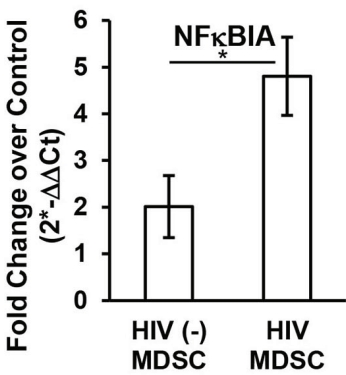

B
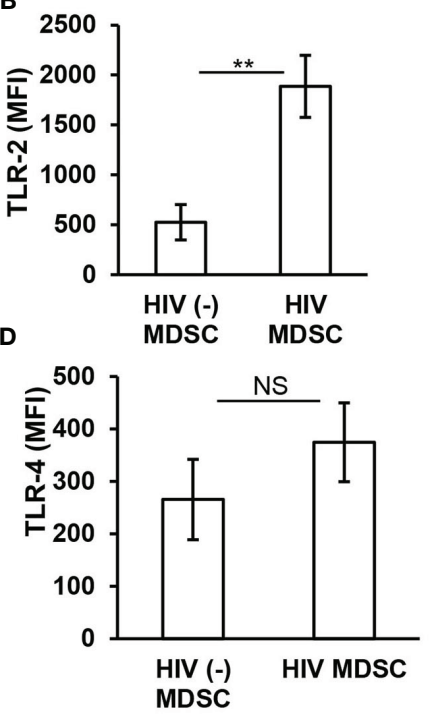

G
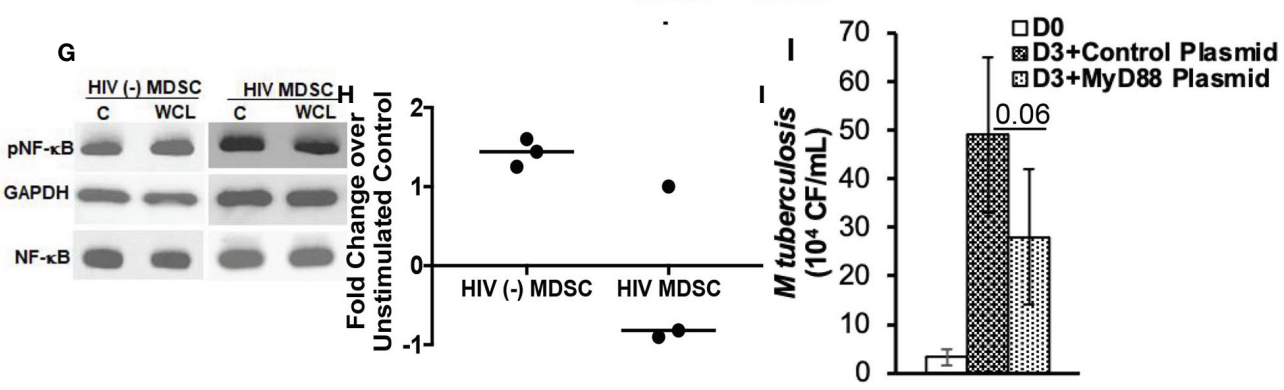

FIGURE 2 | HIV MDSC exhibit truncated TLR signaling. HIV (-) MDSC and HIV MDSC were isolated as in Figure 1. MDSC were surface stained with (A, B) antiTLR2 and (C, D) anti-TLR4 antibodies. The expression of TLR-2 and -4 was determined by flow cytometry and Mean Fluorescence Intensity (MFI) calculated. Representative flow cytometry plots of TLR-2 and -4 are shown; vertical line is median. (E, F) MDSC were cultured without or with $M$ tuberculosis WCL for $24-48$ hours, expression of housekeeping gene $18 \mathrm{~S}$ RNA and MyD88 (E) and NFKBIA (F) and was determined using TaqMan Gene expression assay, and $\Delta \Delta \mathrm{C}_{\mathrm{T}}=\Delta \mathrm{C}_{\mathrm{T}}$, $w_{C L}-\Delta C_{T, \text { control. }}$ The fold change was calculated as $2^{-\left(\Delta \triangle C_{T}\right)}$. (G, $\left.\mathbf{H}\right)$ Total cellular lysates of MDSC cultured without or with $M$ tuberculosis WCL were prepared and

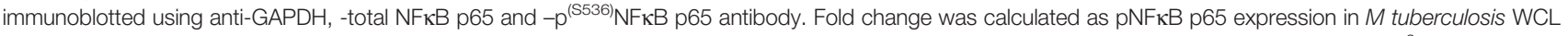
stimulated cells/pNFkB p65 expression in unstimulated cells. Representative Immunoblot of one HIV (-) and HIV (+) donor is shown (G). (I) 0.5 x $10^{6}$ MDSC were transfected with empty vector (Control plasmid) or MyD88 containing expression plasmid (MDSC) using Lipofectamine 3000 reagent. After 16-18 hrs posttransfection, $\mathrm{DR}^{\text {hi }}$ monocytes and MDSC were infected with $M$ tuberculosis at $\mathrm{MOI}$ of 1:5 and $M$ tuberculosis growth (colony forming units (CFU)/ml) was determined in the cellular lysates at day-0 and -3 post-infection (p.i.). For (B, D) histograms are shown for $\mathrm{N}=9 \mathrm{HIV}(-)$ and $\mathrm{N}=17 \mathrm{HIV}(+)$ donors; for (E, F) histograms are shown for $\mathrm{N}=6 \mathrm{HIV}(-)$ and $\mathrm{N}=8 \mathrm{HIV}(+)$ donors; for $\mathbf{( H )}$ dot represents an individual donor; horizontal line represents the median; for (I) histograms shown are for $\mathrm{N}=3$ donors. All histograms show mean values +/- SEM. ${ }^{\star} \mathrm{p}<0.05,{ }^{* *} \mathrm{p}<0.005$. NS, Non Significant.

with $M$ tuberculosis and treated with neutralizing IL-27 antibody $\left(24 \times 10^{4} \pm 9 \times 10^{3}\right.$ vs $\left.12 \times 10^{4} \pm 2 \times 10^{3} \mathrm{CFU} / \mathrm{ml}, \mathrm{p}=0.16\right)$ (Figure 4B), but this remained non-significant.

Next to determine if neutralizing IL-27 and overexpression of MyD88 synergistically affect intracellular replication of $M$ tuberculosis, HIV MDSC were transfected with MyD88 expression plasmid, infected with $M$ tuberculosis and treated with neutralizing IL-27 antibody. Compared to transfection with control vector and isotype matched antibody treatment, MyD88 overexpression and neutralizing IL-27 inhibited intracellular replication of $M$ tuberculosis $\left(16 \times 10^{4} \pm 4 \times 10^{3}\right.$ vs $2 \times 10^{4} \pm$ $0.4 \times 10^{3} \mathrm{CFU} / \mathrm{ml}, \mathrm{p}=0.04$ ) (Figure 4C). All together, these results establish that IL-27 inhibits anti-mycobactericidal activity of HIV MDSC and contributes to the increased 

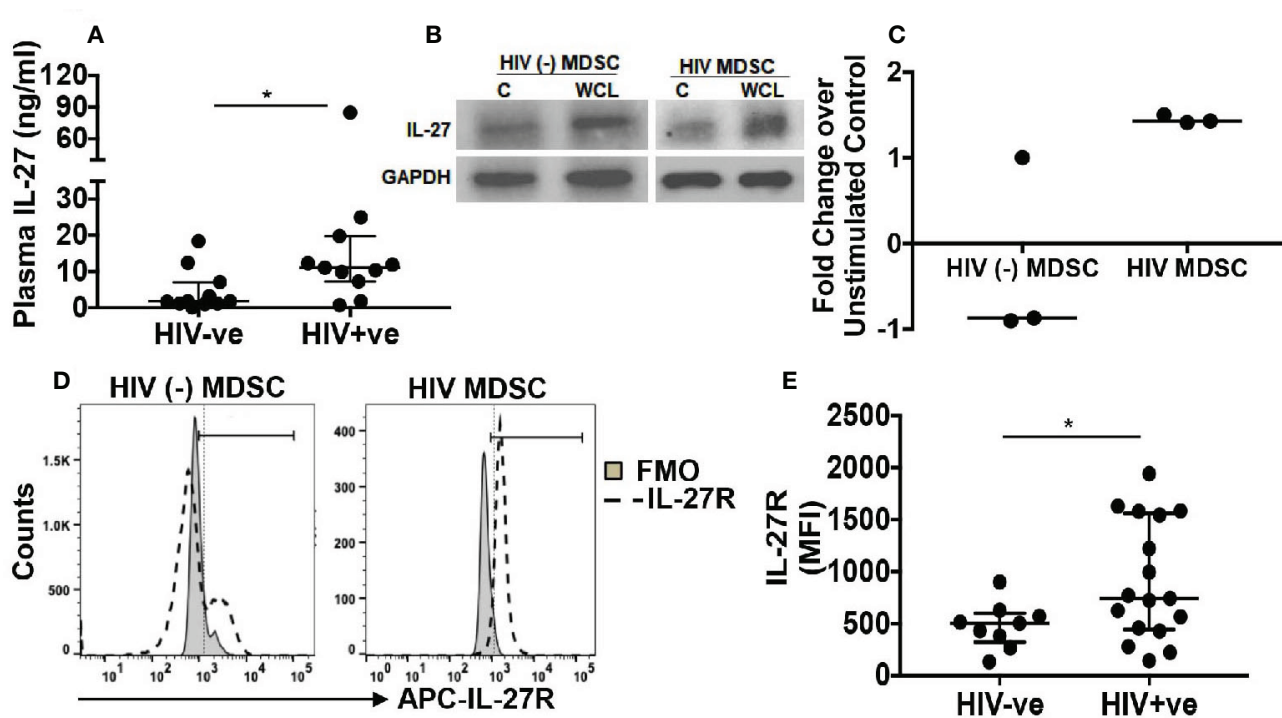

E
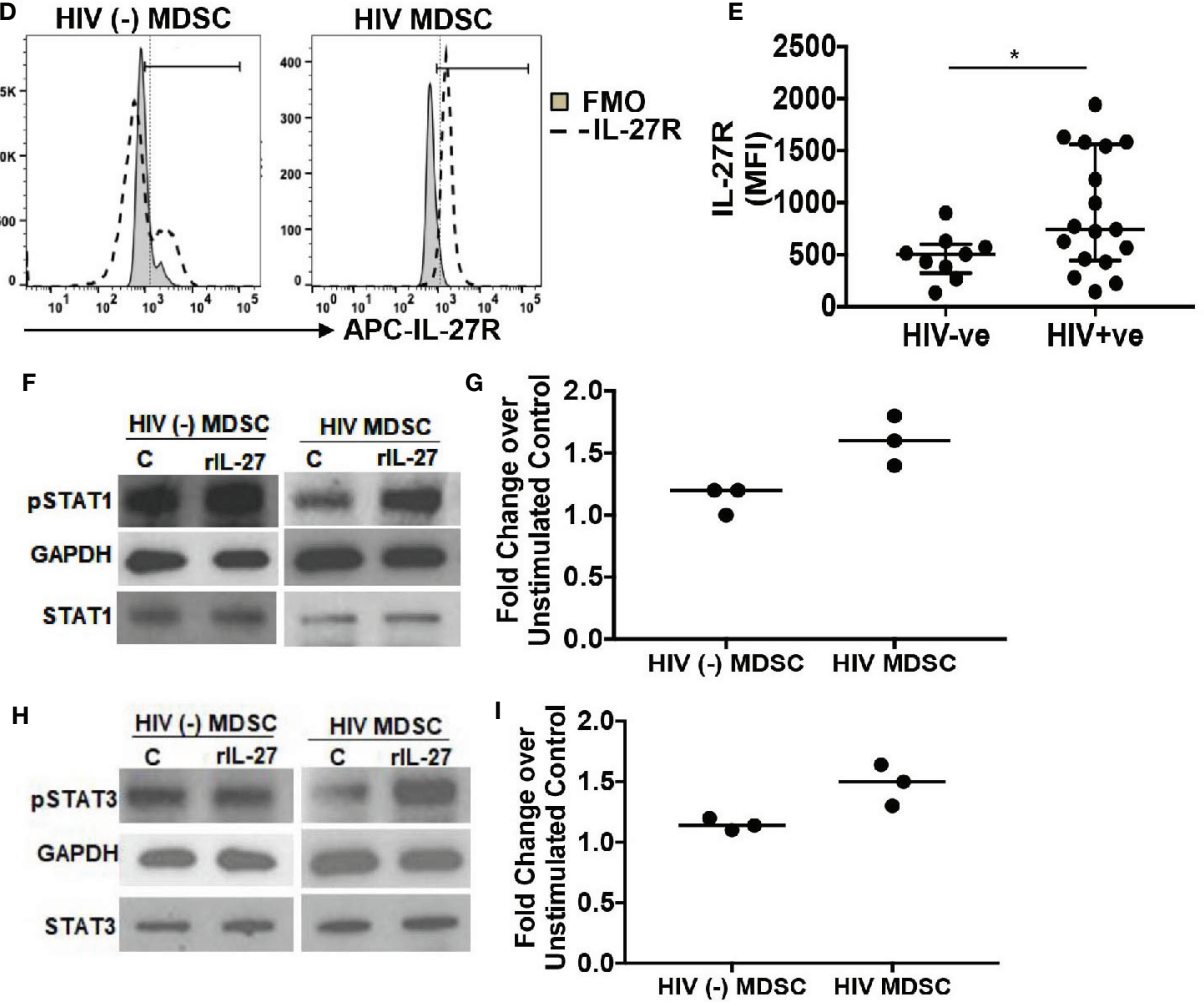

FIGURE 3 | Increased expression of IL-27 and IL-27R by HIV MDSC. To determine the role of IL-27, (A) IL-27 was quantitated in the plasma of HIV (-) and HIV (+) individuals with virologic suppression by ELISA. (B, C) HIV (-) MDSC and HIV MDSC were isolated and cultured without or with M tuberculosis WCL. Total cellular lysates were immunoblotted using anti-GAPDH and -IL-27A antibodies to determine the expression of IL-27p28. Representative Immunoblot of one HIV (-) MDSC and HIV MDSC donor is shown; vertical line is median (B). (D, E) MDSC were isolated and surface stained with anti-IL-27 receptor (IL-27R) antibody. The expression of IL-27R was determined by flow cytometry and Mean Fluorescence Intensity (MFI) calculated. Representative flow cytometry plot is shown (D). (F-I) To determine functional response of IL-27R, MDSC were isolated and stimulated with recombinant IL-27 (rlL-27) for 30-minutes. Total cellular lysates of unstimulated and rIL-27

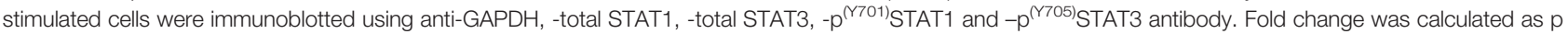
-STAT1 or -STAT3 expression in rlL-27 stimulated cells/as p -STAT1 or -STAT3 expression in unstimulated cells. Representative Immunoblot of one HIV (-) MDSC and HIV MDSC donor is shown. For (A, E), each dot representing an individual donor include observations from $25^{\text {th }}$ to $75^{\text {th }}$ percentile; the horizontal line represents the median value; for $(\mathbf{C}, \mathbf{G}, \mathbf{I})$ each dot represents an individual donor; horizontal line represents the median. ${ }^{*} \mathrm{p}<0.05$.

intracellular replication of $M$ tuberculosis in MDSC of HIVinfected individuals. These studies further suggest that regulating MyD88 and IL-27 augments anti-mycobacterial activity of HIV MDSC.

\section{DISCUSSION}

In HIV- $M$ tuberculosis co-infection, TB can occur at times when $\mathrm{CD} 4^{+} \mathrm{T}$-cell numbers have reconstituted and viral replication is suppressed (4-6). The increased risk of TB in HIV- $M$ tuberculosis co-infection has primarily focused on the defects in $\mathrm{CD}^{+}$and $\mathrm{CD}^{+}$T-cell number and function $(13,48,49)$. However, myeloid cells $\left(\mathrm{CD} 14^{+}\right.$monocytes/macrophages and alveolar macrophages) are the first cells to interact with $M$ tuberculosis and shape T-cell responses; it is important to understand $M$ tuberculosis interaction with these cells and the defects in innate immunity $(10,16,18,50)$. Despite virologic suppression and $\mathrm{CD} 4^{+} \mathrm{T}$-cell recovery, a subset of myeloid cells known as CD14 ${ }^{+}$MDSC are present in HIV-infected individuals 

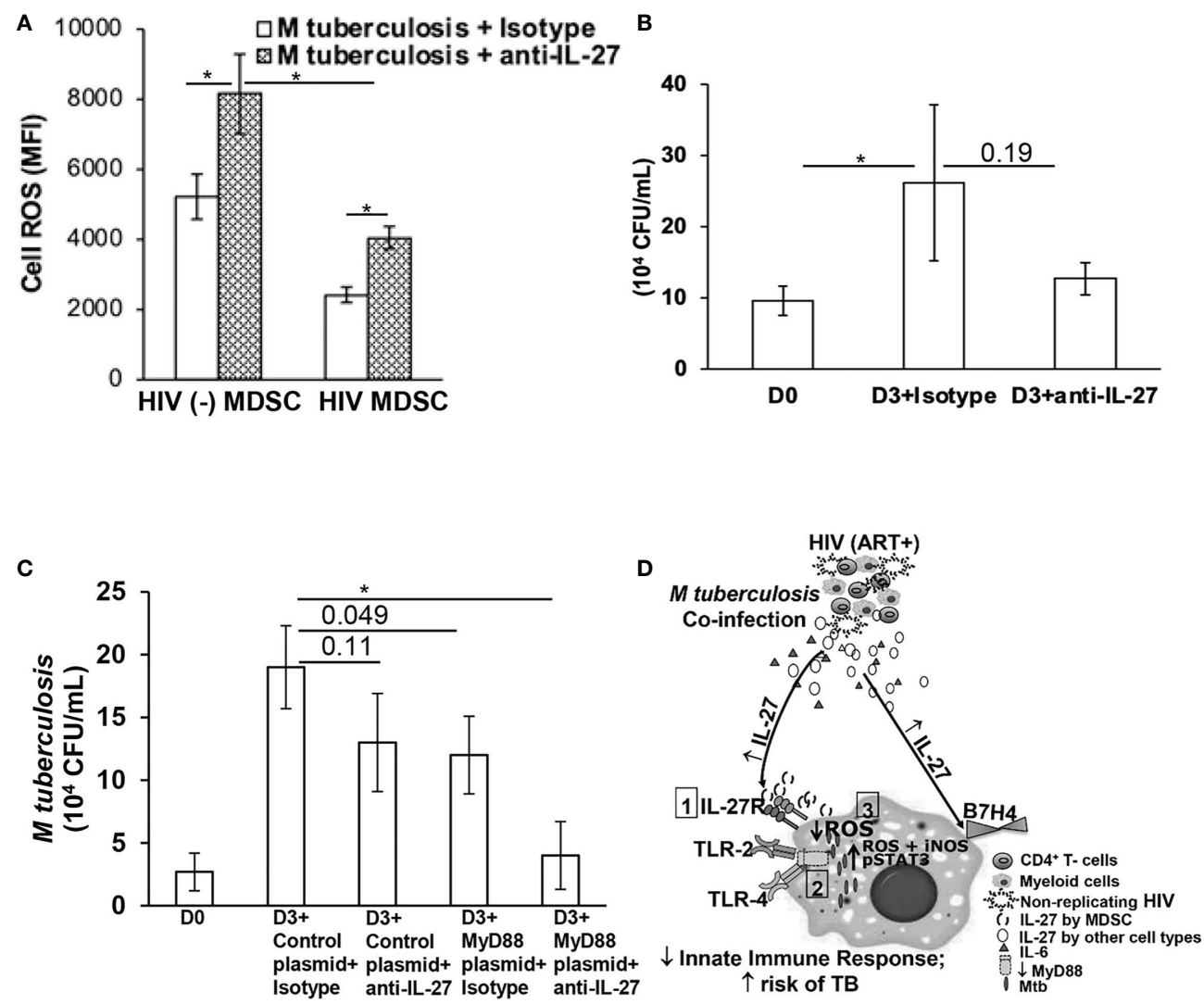

FIGURE 4 | IL-27 inhibits anti-mycobacterial activity of MDSC. To determine that IL-27 inhibits anti-mycobacterial activity of MDSC, HIV (-) MDSC and HIV MDSC were isolated as in Figure 1 using flow cytometry and (A) infected with Mtb-GFP at MOI of 1:5, in the presence of neutralizing IL-27 or isotype matched control antibody for 2-hrs. During last 30-mins of infection $1 \mu \mathrm{M}$ of CellROX deep read reagent was added and subsequently stained with aqua fluorescent LIVE/DEAD stain. Expression of ROS (Cell ROS) in Mtb-GFP+ Live cells was determined by flow cytometry and Mean Fluorescence Intensity (MFI) calculated. Net ROS expression was calculated as in Materials and Methods. (B) MDSC were infected for 3-hrs, washed with PBS to remove extracellular bacteria and cultured with neutralizing IL-27 or isotype matched control antibody. $M$ tuberculosis growth (colony forming units (CFU)/ml) was determined in the cellular lysates at day-0 and -3 post-infection (p.i.). (C) MDSC were transfected with empty (Control) or MyD88 expressing plasmid using Lipofectamine 3000. After 16-18 hrs post-transfection, were infected with $M$ tuberculosis at $\mathrm{MOI}$ of 1:5 for 3-hrs washed with PBS to remove extracellular bacteria and cultured with neutralizing IL-27 or isotype matched control antibody. $M$ tuberculosis growth (colony forming units (CFU)/ml) was determined in the cellular lysates at day-0 and -3 post-infection (p.i.). (D) Regulation of immunity in HIV-Mtb co-infection: HIV-infected individuals on CART with suppressed HIV replication have increased IL-27 and MDSC in these individuals exhibit (1) higher expression of IL27R, (2) lower expression of MyD88 which abrogates TLR-signaling and (3) reduced expression of Reactive Oxide Species (ROS) in response to M tuberculosis. The histograms show mean values $+/$ - SEM; $N=4$ donors. ${ }^{*} p<0.05$.

that down-regulate T-cell response to cytomegalovirus $(30,31)$. In this research, we demonstrate that MDSC isolated from HIV (+) individuals with virologic suppression as compared MDSC isolated from HIV (-) controls exhibit suppressed cytokine production in response to $M$ tuberculosis or WCL. We also demonstrate that $M$ tuberculosis infected HIV MDSC produce less ROS and exhibit a higher intracellular replication. Additionally, we show that the impaired anti-mycobacterial activity of HIV MDSC is through mechanisms involving cytokine IL-27 and truncated TLRsignaling. These support the previous findings demonstrating suppressed innate immune function and increased bacillary load in HIV- $M$ tuberculosis co-infected individuals $(10,17,18,20)$.

MDSC expand during various pathological conditions as a result of acute or chronic inflammation and are important mediators of immune suppression $(21,23-26,29,31,32,51)$. In murine $\mathrm{TB}, \mathrm{MDSC}$ are present at the disease site, harbor mycobacteria, produce cytokines TNF- $\alpha$, IL- $1 \alpha$ and IL- 6 , and suppress anti-mycobacterial T-cell IFN- $\gamma$ responses $(25,33)$. Accumulation of MDSC in lungs heightens TB lethality, and MDSC depletion by all-trans-retinoic acid ameliorates primary progressive TB $(25,52,53)$. MDSC also expand in peripheral blood and pleural fluid of TB patients and HIV-M tuberculosis co-infected children, and suppress $\mathrm{T}$-cell effector functions through mechanisms involving suppressed TNF- $\alpha$, IL-2 and IL-10 (25, 54-56). These findings collectively establish downregulated innate immune responses mediated by MDSC contribute to the failure to control $M$ tuberculosis. However, we provide the first evidence that MDSC present in HIV-infected individuals with virologic suppression are defective in innate immune mediated control of $M$ tuberculosis and are potential mediators of tuberculosis in these individuals. Similar to the previous findings, we also observed that MDSC isolated from 
HIV-infected individuals phagocytose $M$ tuberculosis, thus provide a niche for pathogen survival, increasing the risk of TB $(32,33)$. Unlike the findings of Agarwal et al, we found higher intracellular replication of $M$ tuberculosis and lower quantities of cytokines from HIV MDSC as compared to HIV (-) MDSC (32). Agarwal et al, generated MDSC and monocyte derived macrophages (MDM) in vitro to compare the effect of these cell types on in vitro granuloma; we have utilized a more physiological ex vivo approach to compare the mycobacterial response of MDSC isolated from HIV-infected and -uninfected individuals and did not use any cytokine treatment prior to infection with $M$ tuberculosis. These observed differences in the anti-mycobacterial activity of HIV (-) MDSC and HIV MDSC are suggestive of the impact of HIV on cellular reprogramming of MDSC. Our findings are similar to the in vivo study of Knaul et al. establishing higher mycobacterial load in MDSC isolated from lungs of $M$ tuberculosis susceptible animals (33). A limitation of our study is that we isolated peripheral MDSC from HIV-infected individuals to determine their antimycobacterial activity. Nonetheless, presence of arginase-I and nitric oxide co-expressing MDSC like cells in the necrotic granulomas of $M$ tuberculosis infected macaques $(53,57)$, and accumulation of MDSC in blood at advanced stage of $M$ tuberculosis infection establish that MDSC are critical mediators of tuberculosis disease pathogenesis and suppress both innate and adaptive immune mediated control of $M$ tuberculosis $(25,33,53)$. The increased bacillary load observed in HIV MDSC conceivably is due to higher infectivity of these cells. Owing to a small sample size we were unable to statistically determine this aspect. We are currently investigating the interaction and trafficking of $M$ tuberculosis inside MDSC of HIV- uninfected and -infected individuals. Here we propose that MDSC in virologically suppressed HIV-infected individuals are permissive to $M$ tuberculosis and contribute to increased bacillary load observed in these individuals.

TNF- $\alpha$ and IL12p70 are indispensable to control $M$ tuberculosis; these cytokines enhance phagosome-lysosome maturation, antigen presentation and mobilization of activated T cells (58-60). Asymptomatic HIV-infection is associated with reduced release of TNF- $\alpha$ by alveolar macrophages and peripheral blood mononuclear cells in response to $M$ tuberculosis infection or immunogenic $M$ tuberculosis specific proteins $(61,62)$. This is a result of impaired nuclear translocation of NF- $\kappa \mathrm{B}$, and HIV Nef mediated destabilization of TNF- $\alpha$ mRNA $(61,62)$. Accordingly, we found that $M$ tuberculosis upregulates NFKBI $\alpha$ in HIV MDSC which masks the nuclear localization signals of NF- $\kappa \mathrm{B}$ by stabilizing $\mathrm{I} \kappa \mathrm{B} \alpha$. Additionally, both TNF- $\alpha$ and IL12p70 play an important link between innate and adaptive immune responses. Although yet to be investigated, it is plausible that the reduced $M$ tuberculosis specific cytokines produced by HIV MDSC results in the decreased expression of chemokines CCL5, CXCL9 and CXCL10 thus restricting the migration of $\mathrm{CXCR}^{+}, \mathrm{CCR}^{+}$and $\mathrm{CCR}^{+}$activated $\mathrm{T}$ cells to granuloma or secondary lymphoid tissues, resulting in loss of immunity in HIV- $M$ tuberculosis coinfected individuals $(63,64)$. We previously reported increased
mRNA expression of p47phox subunit of ROS by HIV MDSC, which mediates down regulation of $\mathrm{T}$ cell function (29). Consistently, HIV MDSC produced profound ROS at basal level, but not in response to $M$ tuberculosis infection. Here we show that the reduced release of anti-mycobacterial cytokines by HIV MDSC directly affects the mycobacterial load through mechanism involving ROS suppression. ROS generated by NADPH oxidase is a vital component of $M$ tuberculosis containing mature phagosome, facilitating bacterial killing; ROS also regulates NF- $\kappa \mathrm{B}$ and MAP kinase signaling in TLR-dependent manner (36). Our study affirms that truncated TLR-MyD88 axis in HIV MDSC increases mycobacterial load, which potentially amplifies the risk of tuberculosis in HIV patients with virologic suppression; reconstituting MyD88 partially recovers mycobactericidal activity of HIV MDSC. It is possible that TNF- $\alpha$ and IL12p70 produced by macrophages compensates the suppressed anti-mycobacterial activity of HIV MDSC, but inhibition of monocyte/macrophage function by MDSC observed in tumors cannot be ruled out in HIV$M$ tuberculosis co-infection $(28,65)$.

IL-6 is a pleiotropic proinflammatory cytokine produced by multiple cell types in response to inflammatory stimuli including IL- $1 \beta$, TNF- $\alpha$, TLRs, prostaglandins and stress responses (66, 67). IL-6 deficiency leads to impaired innate and adaptive immunity to viral, bacterial and parasitic infection. Even though, the importance of IL-6 during $M$ tuberculosis infection is not well understood, its neutralization increases susceptibility to infection and mycobacterial load, while delaying T-cell accumulation and IFN $\gamma$ expression, both during primary infection, and vaccination with BCG and a subunit vaccine (68-70). Additionally, IL-6 is critical for differentiation and maintenance of IL-23 dependent $\mathrm{T}_{\mathrm{H}} 17$ cells- important for recruitment of neutrophils to infection site, and IFN $\gamma$ mediated control of $M$ tuberculosis (71-73). IL-23 treatment of $M$ tuberculosis infected animals reduces mycobacterial burden and augments cellular responses; its absence increases mycobacterial burden, and decreases the expression of IL-17, IL-22 and CXCL13 resulting in accumulation of lymphocytes around the vessels rather than within granulomas $(74,75)$. While we did not evaluate $\mathrm{T}$-cell responses in this study, we found comparable level of IL-6, but lower level of IL-23 produced by HIV MDSC as compared to HIV (-) MDSC in response to $M$ tuberculosis (Figure 1A and Supplemental Figures 4A, B). Further studies are needed to determine the exact role of HIV MDSC in suppressing adaptive immunity to $M$ tuberculosis. Chronic immune activation driven by IL- 6 and TNF- $\alpha$ are major predictors of HIV disease progression. Elevated level of IL-6 present in serum, mucosal and lymphoid tissues augment HIV replication through $\mathrm{C} / \mathrm{EBPb}$ mediated binding to the HIV long terminal repeats and inhibition of APOBEC3G (76-81). We and others have established that IL-6 mediates MDSC expansion, and even though its level decline following successful administration of cART, but still remain elevated as compared to healthy controls thus maintaining increased numbers of MDSC in HIV patients with virologic suppression (29-31). These MDSC increase the risk of tuberculosis in HIV- $M$ tuberculosis co-infection. 
IL-27 and IL-27R are expressed by activating myeloid cells including dendritic cells and macrophages, and modulate both macrophage and T-cell activity during $M$ tuberculosis infection $(45,82,83)$. We and others have observed that IL-27 directly inhibits HIV replication (Supplemental Figures 4C, D) in PBMC. Although the mechanism of IL-27 mediated viral suppression is not fully established, it appears that the inhibition of spectrin $\beta$ nonreythrocyte 1 (SPTBN1) by IL-27 plays a critical role (84). In HIV-infected individuals serum IL-27 levels correlate negatively with viral load and positively with $\mathrm{CD}^{+}{ }^{+}$T-cell counts (30), and IL-27 induced IL- 6 and TNF- $\alpha$ production is downregulated in HIV infection (85). This is of significance in the settings of HIV-M tuberculosis co-infection where IL-27 supports clinical recovery from HIV but is detrimental to control $M$ tuberculosis. Previously, Egidio et al. also found increased expression of IL-27 in TB patients coinfected with HIV as compared to latent TB infection in south and southeast African cohorts (82). In this study, we provide the first evidence of the direct effect of IL-27 on $M$ tuberculosis in HIV- $M$ tuberculosis co-infection. Our findings that neutralizing IL-27 augments the expression of ROS in response to $M$ tuberculosis and controls intracellular replication of $M$ tuberculosis corroborate with the findings that, IL-27 negatively regulates macrophage response by inhibiting the expression of phagosomal vacuolar ATPase (V-ATPase) and lysosomal integrated membrane protein-1 (CD63), resulting in suppression of phagosomal acidification and cathepsin D maturation, all these lead to increased bacillary load $(44,45)$. With regard to the expression of IL-27, unlike Egidio et al. and Cory et al, IL-27 transcripts were undetectable in our study (45, 82). The potential reasons for this could be: 1) difference in the samples used, Egidio et al. measured IL-27 gene expression in whole blood RNA (82) and Cory et al. utilized macrophages (45), and 2) the amount of RNA used by Cory et al. for reverse transcription and subsequent transcript analysis was $750 \mathrm{ng}$; given the low numbers of MDSC that could be isolated from $\mathrm{HIV}$-infected individuals, we were unable to obtain such a high quantity of RNA and thus low copies of IL-27 could be present below our detection limit. Of note, p28 subunit specific to IL-27 is produced by activated myeloid cells through TLR-2, -4 and -9 in MyD88 dependent manner (86), and in MyD88 independent manner through TLR-4 - TIR-domain-containing adapter inducing IFN $\beta$ (TRIF) and IFN regulatory factor 3 (IRF3) pathways $(87,88)$. In this research, we show that HIV MDSC are deficient in MyD88 expression, suggesting that a MyD88independent mechanism is the major pathway involved in IL-27 synthesis in response to $M$ tuberculosis. We are currently investigating the mechanism of IL-27 mediated suppression of innate immunity in response to $M$ tuberculosis with or without co-infection with HIV. The increased plasma IL-27 in HIVinfected individuals in this and other studies suggest multiple cell types produce this cytokine and exhibits anti-HIV activity (30, 84). In the present study, we provide the first evidence of increased IL-27 and IL-27R by MDSC in HIV-infected individuals with virologic suppression. We previously showed that IL-27 upregulates B7-H4 expression on MDSC, which regulates T-cell function (30). In this research, we propose that IL-27 in HIV- $M$ tuberculosis co-infection acts on MDSC both in autocrine and paracrine manner, and that IL-27-IL27R axis is a potential mediator of suppressed immunological response to $M$ tuberculosis (Figure 4D).

In summary, our ex vivo and in vitro data collectively establish that HIV-infected individuals with virologic suppression have increased levels of circulating IL-27 and MDSC. MDSC exhibit truncated TLR-mediated innate immunological function in response to $M$ tuberculosis. Further, these MDSC express increased surface expression of IL-27R which may further downregulate the innate immunity to $M$ tuberculosis. These findings provide a mechanistic model of how MDSC can increase the risk of tuberculosis in HIV-M tuberculosis coinfected individuals. Moreover, our findings suggest that IL-27/ IL-27R and MDSC provide attractive biomarkers to assess tuberculosis prognosis during HIV-infection.

\section{DATA AVAILABILITY STATEMENT}

The original contributions presented in the study are included in the article/Supplementary Material. Further inquiries can be directed to the corresponding author.

\section{ETHICS STATEMENT}

The studies involving human participants were reviewed and approved by The University of California San Diego and The University of Georgia Athens. The patients/participants provided their written informed consent to donate blood for this study.

\section{AUTHOR CONTRIBUTIONS}

AG developed the study, performed experiments, analyzed data, and wrote the paper. PN, SP and BS performed the experiments, and analyzed the data. All authors contributed to the article and approved the submitted version.

\section{FUNDING}

This research was supported by AI127132 from the National Institute of Allergy and Infectious Diseases (NIAID) and The University of Georgia Research Foundation.

\section{ACKNOWLEDGMENTS}

We thank Emory University Center for AIDS Research (P30 AI050409), and Stephen A Spector, MD; Department of Pediatrics, Division of Infectious Diseases, University of 
California, San Diego, La Jolla, for providing with the blood samples from HIV-infected individuals. We thank Stephen A Spector for critical reading of the manuscript, and Larry S Schlesinger, MD; Texas Biomedical Research Institute, San Antonio, TX, for providing GFP expressing $M$ tuberculosis Erdman strain. We thank Ms Kimberly Schmitz, Ms Stephanie Croyle and Ms Jennifer Dunlop, Clinical Translational Research Unit, and Ms Katarzyna Rzepka, University of Georgia, for their technical assistance. A part of this work was supported by the National Center for Advancing Translational Sciences of the National Institutes of Health under Award Number UL1TR002378. A part of this work was performed with the support of Flow Cytometry Core at the UC San Diego Center for AIDS Research (P30

\section{REFERENCES}

1. W.H. Organization. Global Tuberculosis Report. World Health Organization. (2015).

2. UNAIDS. Unaids Report on Global Aids Epidemic 2010 (2010). Available at: http://www.unaids.org/documents/20101123_GlobalReport_Chap2_em.pdf.

3. Pawlowski A, Jansson M, Skold M, Rottenberg ME, Kallenius G. Tuberculosis and HIV Co-Infection. PloS Pathog (2012) 8:e1002464. doi: 10.1371/ journal.ppat.1002464

4. Getahun H, Gunneberg C, Granich R, Nunn P. Hiv Infection-Associated Tuberculosis: The Epidemiology and the Response. Clin Infect Dis (2010) 50 Suppl 3:S201-7. doi: 10.1086/651492

5. Girardi E, Sabin CA, d'Arminio Monforte A, Hogg B, Phillips AN, Gill MJ, et al. Incidence of Tuberculosis Among HIV-infected Patients Receiving Highly Active Antiretroviral Therapy in Europe and North America. Clin Infect Dis (2005) 41:1772-82. doi: 10.1086/498315

6. Gupta A, Wood R, Kaplan R, Bekker LG, Lawn SD. Tuberculosis Incidence Rates During 8 Years of Follow-Up of an Antiretroviral Treatment Cohort in South Africa: Comparison With Rates in the Community. PloS One (2012) 7: e34156. doi: 10.1371/journal.pone.0034156

7. Schluger NW, Perez D, Liu YM. Reconstitution of Immune Responses to Tuberculosis in Patients With HIV Infection Who Receive Antiretroviral Therapy. Chest (2002) 122:597-602. doi: 10.1378/chest.122.2.597

8. Sutherland R, Yang H, Scriba TJ, Ondondo B, Robinson N, Conlon C, et al. Impaired IFN-gamma-secreting Capacity in Mycobacterial Antigen-Specific Cd4 T Cells During Chronic HIV-1 Infection Despite Long-Term Haart. AIDS (2006) 20:821-9. doi: 10.1097/01.aids.0000218545.31716.a4

9. Bezuidenhout J, Roberts T, Muller L, van Helden P, Walzl G. Pleural Tuberculosis in Patients With Early Hiv Infection is Associated With Increased TNF-Alpha Expression and Necrosis in Granulomas. PloS One (2009) 4:e4228. doi: 10.1371/journal.pone.0004228

10. Noursadeghi M, Tsang J, Miller RF, Straschewski S, Kellam P, Chain BM, et al. Genome-Wide Innate Immune Responses in HIV-1-infected Macrophages are Preserved Despite Attenuation of the NF-Kappa B Activation Pathway. J Immunol (2009) 182:319-28. doi: 10.4049/jimmunol.182.1.319

11. Tomlinson GS, Bell LC, Walker NF, Tsang J, Brown JS, Breen R, et al. Hiv-1 Infection of Macrophages Dysregulates Innate Immune Responses to Mycobacterium Tuberculosis by Inhibition of Interleukin-10. J Infect Dis (2014) 209:1055-65. doi: 10.1093/infdis/jit621

12. Hersperger AR, Martin JN, Shin LY, Sheth PM, Kovacs CM, Cosma GL, et al. Increased HIV-specific Cd8+ T-Cell Cytotoxic Potential in HIV Elite Controllers is Associated With T-Bet Expression. Blood (2011) 117:3799808. doi: 10.1182/blood-2010-12-322727

13. Kalokhe AS, Adekambi T, Ibegbu CC, Ray SM, Day CL, Rengarajan J. Impaired Degranulation and Proliferative Capacity of Mycobacterium Tuberculosis-Specific Cd8+ T Cells in HIV-infected Individuals With Latent Tuberculosis. J Infect Dis (2015) 211:635-40. doi: 10.1093/infdis/jiu505

14. Woodworth JS, Wu Y, Behar SM. Mycobacterium Tuberculosis-Specific Cd8+ T Cells Require Perforin to Kill Target Cells and Provide Protection In Vivo. J Immunol (2008) 181:8595-603. doi: 10.4049/jimmunol.181.12.8595
AI036214), the VA San Diego Health Care System, and the San Diego Veterans Medical Research Foundation. We thank Ms Tara Rambaldo and Mr Neal Sekia, CFAR, University of California, San Diego, and Ms Julie Nelson, Center for Tropical and Emerging Global Diseases Flow Cytometry Core, University of Georgia, Athens GA for their assistance with flow cytometry.

\section{SUPPLEMENTARY MATERIAL}

The Supplementary Material for this article can be found online at: https://www.frontiersin.org/articles/10.3389/fimmu.2021. 647019/full\#supplementary-material

15. Campbell GR, Spector SA. Vitamin D Inhibits Human Immunodeficiency Virus Type 1 and Mycobacterium Tuberculosis Infection in Macrophages Through the Induction of Autophagy. PloS Pathog (2012) 8:e1002689. doi: 10.1371/journal.ppat.1002689

16. Deretic V, Vergne I, Chua J, Master S, Singh SB, Fazio JA, et al. Endosomal Membrane Traffic: Convergence Point Targeted by Mycobacterium Tuberculosis and HIV. Cell Microbiol (2004) 6:999-1009. doi: 10.1111/ j.1462-5822.2004.00449

17. Mwandumba HC, Russell DG, Nyirenda MH, Anderson J, White SA, Molyneux ME, et al. Mycobacterium Tuberculosis Resides in Nonacidified Vacuoles in Endocytically Competent Alveolar Macrophages From Patients With Tuberculosis and HIV Infection. J Immunol (2004) 172:4592-8. doi: 10.4049/jimmunol.172.7.4592

18. Patel NR, Swan K, Li X, Tachado SD, Koziel H, Impaired M. TuberculosisMediated Apoptosis in Alveolar Macrophages From Hiv+ Persons: Potential Role of IL-10 and BCL-3. J Leukoc Biol (2009) 86:53-60. doi: 10.1189/ jlb.0908574

19. Rosas-Taraco AG, Arce-Mendoza AY, Caballero-Olin G, Salinas-Carmona MC. Mycobacterium Tuberculosis Upregulates Coreceptors CCR5 and CXCR4 While HIV Modulates CD14 Favoring Concurrent Infection. AIDS Res Hum Retroviruses (2006) 22:45-51. doi: 10.1089/aid.2006.22.45

20. Spear GT, Kessler HA, Rothberg L, Phair J, Landay AL. Decreased Oxidative Burst Activity of Monocytes From Asymptomatic HIV-Infected Individuals. Clin Immunol Immunopathol (1990) 54:184-91. doi: 10.1016/0090-1229(90) 90080-A

21. Greten TF, Manns MP, Korangy F. Myeloid Derived Suppressor Cells in Human Diseases. Int Immunopharmacol (2011) 11:802-7. doi: 10.1016/ j.intimp.2011.01.003

22. Hoechst B, Ormandy LA, Ballmaier M, Lehner F, Kruger C, Manns MP, et al. A New Population of Myeloid-Derived Suppressor Cells in Hepatocellular Carcinoma Patients Induces Cd4(+)Cd25(+)Foxp3(+) T Cells. Gastroenterology (2008) 135:234-43.

23. Poschke I, Mougiakakos D, Hansson J, Masucci GV, Kiessling R. Immature Immunosuppressive CD14+HLA-DR-/Low Cells in Melanoma Patients are Stat3hi and Overexpress Cd80, CD83, and DC-Sign. Cancer Res (2010) 70:4335-45. doi: 10.1158/0008-5472.CAN-09-3767

24. Youn JI, Nagaraj S, Collazo M, Gabrilovich DI. Subsets of Myeloid-Derived Suppressor Cells in Tumor-Bearing Mice. J Immunol (2008) 181:5791-802. doi: 10.4049/jimmunol.181.8.5791

25. du Plessis N, Loebenberg L, Kriel M, von Groote-Bidlingmaier F, Ribechini E, Loxton AG, et al. Increased Frequency of Myeloid-Derived Suppressor Cells During Active Tuberculosis and After Recent Mycobacterium Tuberculosis Infection Suppresses T-Cell Function. Am J Respir Crit Care Med (2013) 188:724-32. doi: 10.1164/rccm.201302-0249OC

26. Gabrilovich DI, Nagaraj S. Myeloid-Derived Suppressor Cells as Regulators of the Immune System. Nat Rev Immunol (2009) 9:162-74. doi: 10.1038/nri2506

27. Ostrand-Rosenberg S. Myeloid-Derived Suppressor Cells: More Mechanisms for Inhibiting Antitumor Immunity. Cancer Immunol Immunother (2010) 59:1593-600. doi: 10.1007/s00262-010-0855-8

28. Sinha P, Clements VK, Bunt SK, Albelda SM, Ostrand-Rosenberg S. CrossTalk Between Myeloid-Derived Suppressor Cells and Macrophages Subverts 
Tumor Immunity Toward a Type 2 Response. J Immunol (2007) 179:977-83. doi: 10.4049/jimmunol.179.2.977

29. Garg A, Spector SA. Hiv Type 1 Gp120-Induced Expansion of Myeloid Derived Suppressor Cells is Dependent on Interleukin 6 and Suppresses Immunity. J Infect Dis (2014) 209:441-51. doi: 10.1093/infdis/jit469

30. Garg A, Trout R, Spector SA. Human Immunodeficiency Virus Type-1 Myeloid Derived Suppressor Cells Inhibit Cytomegalovirus Inflammation Through Interleukin-27 and B7-H4. Sci Rep (2017) 7:44485. doi: 10.1038/ srep44485

31. Qin A, Cai W, Pan T, Wu K, Yang Q, Wang N, et al. Expansion of Monocytic Myeloid-Derived Suppressor Cells Dampens T Cell Function in HIV-1seropositive Individuals. J Virol (2013) 87:1477-90. doi: 10.1128/JVI.01759-12

32. Agrawal N, Streata I, Pei G, Weiner J, Kotze L, Bandermann S, et al. Human Monocytic Suppressive Cells Promote Replication of Mycobacterium Tuberculosis and Alter Stability of in Vitro Generated Granulomas. Front Immunol (2018) 9:2417. doi: 10.3389/fimmu.2018.02417

33. Knaul JK, Jorg S, Oberbeck-Mueller D, Heinemann E, Scheuermann L, Brinkmann V, et al. Lung-Residing Myeloid-Derived Suppressors Display Dual Functionality in Murine Pulmonary Tuberculosis. Am J Respir Crit Care Med (2014) 190:1053-66. doi: 10.1164/rccm.201405-08280C

34. Garg A. Analysis of Antimicrobial Activity of Monocytic Myeloid Derived Suppressor Cells in vInfection With Mycobacterium Tuberculosis and Human Immunodeficiency Virus. Methods Mol Biol book Ser (MIMB) (part Springer Nature). (2021) 2236:115-27.

35. Cooper AM, Segal BH, Frank AA, Holland SM, Orme IM. Transient Loss of Resistance to Pulmonary Tuberculosis in p47(phox-/-) Mice. Infect Immun (2000) 68:1231-4. doi: 10.1128/IAI.68.3.1231-1234.2000

36. Yang CS, Shin DM, Kim KH, Lee ZW, Lee CH, Park SG, et al. Nadph Oxidase 2 Interaction With TLR2 is Required for Efficient Innate Immune Responses to Mycobacteria Via Cathelicidin Expression. J Immunol (2009) 182:3696705. doi: 10.4049/jimmunol.0802217

37. Courtois G, Smahi A, Reichenbach J, Doffinger R, Cancrini C, Bonnet M, et al. A Hypermorphic Ikappabalpha Mutation is Associated With Autosomal Dominant Anhidrotic Ectodermal Dysplasia and T Cell Immunodeficiency. J Clin Invest (2003) 112:1108-15. doi: 10.1172/JCI18714

38. Ferreiro DU, Komives EA. Molecular Mechanisms of System Control of NFkappaB Signaling by Ikappabalpha. Biochemistry (2010) 49:1560-7.

39. Hayden MS, Ghosh S. Shared Principles in NF-kappaB Signaling. Cell (2008) 132:344-62.

40. Devalraju KP, Neela VSK, Gaddam R, Chaudhury A, Van A, Krovvidi SS, et al. Defective MyD88 and IRAK4 But Not Tlr-2 Expression in HIV+ Individuals With Latent Tuberculosis Infection. Cytokine (2018) 110:213-21.

41. Pathak S, De Souza GA, Salte T, Wiker HG, Asjo B. Hiv Induces Both a DownRegulation of IRAK-4 That Impairs Tlr Signalling and an Up-Regulation of the Antibiotic Peptide Dermcidin in Monocytic Cells. Scand J Immunol (2009) 70:264-76.

42. Scanga CA, Bafica A, Feng CG, Cheever AW, Hieny S, Sher A. Myd88Deficient Mice Display a Profound Loss in Resistance to Mycobacterium Tuberculosis Associated With Partially Impaired Th1 Cytokine and Nitric Oxide Synthase 2 Expression. Infect Immun (2004) 72:2400-4.

43. Fitzgerald KA, Palsson-McDermott EM, Bowie AG, Jefferies CA, Mansell AS, Brady G, et al. Mal (MyD88-adapter-like) is Required for Toll-Like Receptor-4 Signal Transduction. Nature (2001) 413:78-83. doi: 10.1038/35092578

44. Jung JY, Robinson CM. Interleukin-27 Inhibits Phagosomal Acidification by Blocking Vacuolar Atpases. Cytokine (2013) 62:202-5. doi: 10.1016/ j.cyto.2013.03.010

45. Jung JY, Robinson CM. Il-12 and IL-27 Regulate the Phagolysosomal Pathway in Mycobacteria-Infected Human Macrophages. Cell Commun Signal (2014) 1216:12-6. doi: 10.1186/1478-811X-12-16

46. Guzzo C, Che Mat NF, Gee K. Interleukin-27 Induces a STAT1/3- and NFkappaB-dependent Proinflammatory Cytokine Profile in Human Monocytes. J Biol Chem (2010) 285:24404-11. doi: 10.1074/jbc.M110.112599

47. Iyer SS, Ghaffari AA, Cheng G. Lipopolysaccharide-Mediated IL-10 Transcriptional Regulation Requires Sequential Induction of Type I Ifns and IL-27 in Macrophages. J Immunol (2010) 185:6599-607. doi: 10.4049/ jimmunol.1002041

48. Geldmacher C, Ngwenyama N, Schuetz A, Petrovas C, Reither K, Heeregrave EJ, et al. Preferential Infection and Depletion of Mycobacterium Tuberculosis-
Specific Cd4 T Cells After Hiv-1 Infection. J Exp Med (2010) 207:2869-81. doi: $10.1084 /$ jem. 20100090

49. Geldmacher C, Schuetz A, Ngwenyama N, Casazza JP, Sanga E, Saathoff E, et al. Early Depletion of Mycobacterium Tuberculosis-Specific T Helper 1 Cell Responses After Hiv-1 Infection. J Infect Dis (2008) 198:1590-8. doi: 10.1086/ 593017

50. Pathak S, Wentzel-Larsen T, Asjo B. Effects of in Vitro Hiv-1 Infection on Mycobacterial Growth in Peripheral Blood Monocyte-Derived Macrophages. Infect Immun (2010) 78:4022-32. doi: 10.1128/IAI.00106-10

51. Dorhoi A, Kotze LA, Berzofsky JA, Sui Y, Gabrilovich DI, Garg A, et al. Therapies for Tuberculosis and AIDS: Myeloid-Derived Suppressor Cells in Focus. J Clin Invest (2020) 130:2789-99. doi: 10.1172/JCI136288

52. Martino A, Badell E, Abadie V, Balloy V, Chignard M, Mistou MY, et al. Mycobacterium Bovis Bacillus Calmette-Guerin Vaccination Mobilizes Innate Myeloid-Derived Suppressor Cells Restraining In Vivo T Cell Priming Via IL1R-dependent Nitric Oxide Production. J Immunol (2010) 184:2038-47. doi: 10.4049/jimmunol.0903348

53. Tsiganov EN, Verbina EM, Radaeva TV, Sosunov VV, Kosmiadi GA, Nikitina IY, et al. Gr-1dimcd11b+ Immature Myeloid-Derived Suppressor Cells But Not Neutrophils are Markers of Lethal Tuberculosis Infection in Mice. J Immunol (2014) 192:4718-27. doi: 10.4049/jimmunol.1301365

54. Du Plessis N, Jacobs R, Gutschmidt A, Fang Z, van Helden PD, Lutz MB, et al. Phenotypically Resembling Myeloid Derived Suppressor Cells are Increased in Children With HIV and Exposed/Infected With Mycobacterium Tuberculosis. Eur J Immunol (2017) 47:107-18. doi: 10.1002/eji.201646658

55. El Daker S, Sacchi A, Tempestilli M, Carducci C, Goletti D, Vanini V, et al. Granulocytic Myeloid Derived Suppressor Cells Expansion During Active Pulmonary Tuberculosis is Associated With High Nitric Oxide Plasma Level. PloS One (2015) 10:e0123772. doi: 10.1371/journal.pone.0123772

56. Yang B, Wang X, Jiang J, Zhai F, Cheng X. Identification of CD244-expressing Myeloid-Derived Suppressor Cells in Patients With Active Tuberculosis. Immunol Lett (2014) 158:66-72. doi: 10.1016/j.imlet.2013.12.003

57. Mattila JT, Ojo OO, Kepka-Lenhart D, Marino S, Kim JH, Eum SY, et al. Microenvironments in Tuberculous Granulomas are Delineated by Distinct Populations of Macrophage Subsets and Expression of Nitric Oxide Synthase and Arginase Isoforms. J Immunol (2013) 191:773-84. doi: 10.4049/ jimmunol.1300113

58. Harris J, Hope JC, Keane J. Tumor Necrosis Factor Blockers Influence Macrophage Responses to Mycobacterium Tuberculosis. J Infect Dis (2008) 198:1842-50. doi: 10.1086/593174

59. Ramachandra L, Simmons D, Harding CV. Mhc Molecules and Microbial Antigen Processing in Phagosomes. Curr Opin Immunol (2009) 21:98-104. doi: 10.1016/j.coi.2009.01.001

60. Winau F, Weber S, Sad S, de Diego J, Hoops SL, Breiden B, et al. Apoptotic Vesicles Crossprime Cd8 T Cells and Protect Against Tuberculosis. Immunity (2006) 24:105-17. doi: 10.1016/j.immuni.2005.12.001

61. Patel NR, Zhu J, Tachado SD, Zhang J, Wan Z, Saukkonen J, et al. Hiv Impairs TNF-Alpha Mediated Macrophage Apoptotic Response to Mycobacterium Tuberculosis. J Immunol (2007) 179:6973-80. doi: 10.4049/ jimmunol.179.10.6973

62. Kumawat K, Pathak SK, Spetz AL, Kundu M, Basu J. Exogenous Nef is an Inhibitor of Mycobacterium Tuberculosis-Induced Tumor Necrosis Factor-Alpha Production and Macrophage Apoptosis. J Biol Chem (2010) 285:12629-37. doi: 10.1074/jbc.M109.073320

63. Cole KE, Strick CA, Paradis TJ, Ogborne KT, Loetscher M, Gladue RP, et al. Interferon-Inducible T Cell Alpha Chemoattractant (I-Tac): A Novel NonELR Cxc Chemokine With Potent Activity on Activated T Cells Through Selective High Affinity Binding to CXCR3. J Exp Med (1998) 187:2009-21. doi: 10.1084/jem.187.12.2009

64. Griffith JW, Sokol CL, Luster AD. Chemokines and Chemokine Receptors: Positioning Cells for Host Defense and Immunity. Annu Rev Immunol (2014) 32:659-702. doi: 10.1146/annurev-immunol-032713-120145

65. Cao S, Liu J, Chesi M, Bergsagel PL, Ho IC, Donnelly RP, et al. Differential Regulation of IL-12 and IL-10 Gene Expression in Macrophages by the Basic Leucine Zipper Transcription Factor c-Maf Fibrosarcoma. J Immunol (2002) 169:5715-25. doi: 10.4049/jimmunol.169.10.5715

66. Hunter CA, Jones SA. IL-6 as a Keystone Cytokine in Health and Disease. Nat Immunol (2015) 16:448-57. doi: 10.1038/ni.3153 
67. Van Snick J. Interleukin-6: An Overview. Annu Rev Immunol (1990) 8:253-78. doi: 10.1146/annurev.iy.08.040190.001345

68. Ladel CH, Blum C, Dreher A, Reifenberg K, Kopf M, Kaufmann SH. Lethal Tuberculosis in Interleukin-6-Deficient Mutant Mice. Infect Immun (1997) 65:4843-9. doi: 10.1128/IAI.65.11.4843-4849.1997

69. Leal IS, Smedegard B, Andersen P, Appelberg R. Interleukin-6 and Interleukin-12 Participate in Induction of a Type 1 Protective T-Cell Response During Vaccination With a Tuberculosis Subunit Vaccine. Infect Immun (1999) 67:5747-54. doi: 10.1128/IAI.67.11.5747-5754.1999

70. Saunders BM, Frank AA, Orme IM, Cooper AM. Interleukin-6 Induces Early Gamma Interferon Production in the Infected Lung But is Not Required for Generation of Specific Immunity to Mycobacterium Tuberculosis Infection. Infect Immun (2000) 68:3322-6. doi: 10.1128/IAI.68.6.3322-3326.2000

71. Ivanov II, McKenzie BS, Zhou L, Tadokoro CE, Lepelley A, Lafaille JJ, et al. The Orphan Nuclear Receptor Rorgammat Directs the Differentiation Program of Proinflammatory Il-17+ T Helper Cells. Cell (2006) 126:112133. doi: 10.1016/j.cell.2006.07.035

72. Stritesky GL, Yeh N, Kaplan MH. Il-23 Promotes Maintenance But Not Commitment to the Th17 Lineage. J Immunol (2008) 181:5948-55. doi: 10.4049/jimmunol.181.9.5948

73. Khader SA, Bell GK, Pearl JE, Fountain JJ, Rangel-Moreno J, Cilley GE, et al. Il-23 and IL-17 in the Establishment of Protective Pulmonary Cd4+ T Cell Responses After Vaccination and During Mycobacterium Tuberculosis Challenge. Nat Immunol (2007) 8:369-77. doi: 10.1038/ni1449

74. Khader SA, Guglani L, Rangel-Moreno J, Gopal R, Junecko BA, Fountain JJ, et al. Il-23 is Required for Long-Term Control of Mycobacterium Tuberculosis and B Cell Follicle Formation in the Infected Lung. J Immunol (2011) 187:5402-7. doi: 10.4049/jimmunol.1101377

75. Happel KI, Lockhart EA, Mason CM, Porretta E, Keoshkerian E, Odden AR, et al. Pulmonary Interleukin-23 Gene Delivery Increases Local T-Cell Immunity and Controls Growth of Mycobacterium Tuberculosis in the Lungs. Infect Immun (2005) 73:5782-8. doi: 10.1128/IAI.73.9.5782-5788.2005

76. Cervia JS, Chantry CJ, Hughes MD, Alvero C, Meyer WA,3, Hodge J, et al. Associations of Proinflammatory Cytokine Levels With Lipid Profiles, Growth, and Body Composition in HIV-infected Children Initiating or Changing Antiretroviral Therapy. Pediatr Infect Dis J (2010) 29:1118-22. doi: 10.1097/INF.0b013e3181ed9f4c

77. Rychert J, Strick D, Bazner S, Robinson J, Rosenberg E. Detection of HIV gp120 in Plasma During Early Hiv Infection is Associated With Increased Proinflammatory and Immunoregulatory Cytokines. AIDS Res Hum Retroviruses (2010) 26:1139-45. doi: 10.1089/aid.2009.0290

78. Henderson AJ, Zou X, Calame KL. C/Ebp Proteins Activate Transcription From the Human Immunodeficiency Virus Type 1 Long Terminal Repeat in Macrophages/Monocytes. J Virol (1995) 69:5337-44. doi: 10.1128/ JVI.69.9.5337-5344.1995

79. Kinoshita SM, Taguchi S. Nf-IL6 (C/Ebpbeta) Induces Hiv-1 Replication by Inhibiting Cytidine Deaminase Apobec3g. Proc Natl Acad Sci USA (2008) 105:15022-7. doi: 10.1073/pnas.0807269105
80. Kalayjian RC, Machekano RN, Rizk N, Robbins GK, Gandhi RT, Rodriguez BA, et al. Pretreatment Levels of Soluble Cellular Receptors and Interleukin-6 are Associated With HIV Disease Progression in Subjects Treated With Highly Active Antiretroviral Therapy. J Infect Dis (2010) 201:1796-805. doi: $10.1086 / 652750$

81. Glushakova S, Baibakov B, Margolis LB, Zimmerberg J. Infection of Human Tonsil Histocultures: A Model for HIV Pathogenesis. Nat Med (1995) 1:1320-2. doi: 10.1038/nm1295-1320

82. Torrado E, Fountain JJ, Liao M, Tighe M, Reiley WW, Lai RP, et al. Interleukin 27r Regulates Cd4+ T Cell Phenotype and Impacts Protective Immunity During Mycobacterium Tuberculosis Infection. J Exp Med (2015) 212:1449-63. doi: $10.1084 /$ jem.20141520

83. Pirhonen J, Siren J, Julkunen I, Matikainen S. IFN-Alpha Regulates Toll-Like Receptor-Mediated Il-27 Gene Expression in Human Macrophages. J Leukoc Biol (2007) 82:1185-92. doi: 10.1189/jlb.0307157

84. Dai L, Lidie KB, Chen Q, Adelsberger JW, Zheng X, Huang D, et al. Il-27 Inhibits Hiv-1 Infection in Human Macrophages by Down-Regulating Host Factor Sptbn1 During Monocyte to Macrophage Differentiation. J Exp Med (2013) 210:517-34. doi: 10.1084/jem.20120572

85. Guzzo C, Hopman WM, Che Mat NF, Wobeser W, Gee K. IL-27-Induced Gene Expression is Downregulated in HIV-infected Subjects. PloS One (2012) 7:e45706. doi: 10.1371/journal.pone.0045706

86. Liu J, Guan X, Ma X. Regulation of IL-27 P28 Gene Expression in Macrophages Through MyD88- and Interferon-Gamma-Mediated Pathways. J Exp Med (2007) 204:141-52. doi: 10.1084/jem.20061440

87. Molle C, Nguyen M, Flamand V, Renneson J, Trottein F, De Wit D, et al. Il-27 Synthesis Induced by TLR Ligation Critically Depends on IFN Regulatory Factor 3. J Immunol (2007) 178:7607-15. doi: 10.4049/ jimmunol.178.12.7607

88. Zhang J, Qian X, Ning H, Yang J, Xiong H, Liu J. Activation of IL-27 P28 Gene Transcription by Interferon Regulatory Factor 8 in Cooperation With Interferon Regulatory Factor 1. J Biol Chem (2010) 285:21269-81. doi: 10.1074/jbc.M110.100818

Disclaimer: The content is solely the responsibility of the authors and does not necessarily represent the official views of the National Institutes of Health.

Conflict of Interest: The authors declare that the research was conducted in the absence of any commercial or financial relationships that could be construed as a potential conflict of interest.

Copyright $(2) 2021$ Namdev, Patel, Sparling and Garg. This is an open-access article distributed under the terms of the Creative Commons Attribution License (CC BY). The use, distribution or reproduction in other forums is permitted, provided the original author(s) and the copyright owner(s) are credited and that the original publication in this journal is cited, in accordance with accepted academic practice. No use, distribution or reproduction is permitted which does not comply with these terms. 